\title{
A política educacional do primeiro governo petista de São Carlos-SP (2001-2004)
}

Ana Paula Rodrigues da Silva*

Amarilio Ferreira Junior**

\section{Resumo}

0 artigo propõe uma avaliação da política educacional implementada pelo primeiro governo do Partido dos Trabalhadores no município de São Carlos (SP), entre 2001 e 2004. Nesse período, o panorama educacional brasileiro já estava marcado, desde a ditadura militar (1964-1985), por uma ampla gama de experiências e reformas, as quais tiveram como um de seus resultados mais importantes a universalização do acesso à escolaridade obrigatória já no final da década de 90 . Resolvida a questão quantitativa, o grande problema a ser enfrentado passou a ser o da qualidade do ensino ofertado na escola pública. Apesar da situação privilegiada da cidade de São Carlos, situada numa das regiões economicamente mais ricas do país e com forte tradição educacional, nossas pesquisas nos levam a afirmar que a primeira gestão petista do município deveria ter materializado uma política educacional mais efetiva do que aquela implementada, a fim de atingir a melhoria da qualidade do ensino ofertado à população.

Palavras-chave: Política educacional. Partido dos Trabalhadores. Democratização da educação.

\section{The Educational Policy of The Workers Party's First Government In São Carlos - SP (2001-2004)}

\section{Abstract}

The article proposes an evaluation of the educational policy implemented by the Workers Party's first government in the municipality of São Carlos (SP), from 2001 to 2004. In that period, the Brazilian educational panorama had already been marked, since the military regime (1964-1985), by a wide range of

\footnotetext{
Mestre em Educação, Universidade Federal de São Carlos (UFSCar), SP. E-mail: anapaulars@ufscar.br. .. Doutor em História Social, Universidade de São Paulo (USP); Professor do Departamento de Educação da UFSCar, SP. E-mail: ferreira@ufscar.br.
} 
experiences and reforms, which had as one of their more important results the universalization of the access to the obligatory education by the end of the 1990 's. With the quantitative issue solved, the biggest problem to be faced is the quality of teaching offered by the public school. In spite of São Carlos' privileged situation, located in one of the richest areas in the country and having strong educational tradition, our research makes us conclude that the Workers Party's first government in the city should have materialized a much more effective educational policy than the one really implemented, in order to reach the improvement on the quality of teaching offered to the population. Keywords: Educational policy, Workers Party, Democratization of education

\section{La politica educativa del primer gobierno del Partido de los Trabajadores de São Carlos - ciudad del interior de San Pablo (2001-2004) \\ Resumen}

El artículo propone una evaluación de la política educativa implementada por el primer gobierno del Partido de los Trabajadores (PT) en la ciudad de São Carlos (SP), entre 2001 y 2004. En este período, el panorama educativo brasileño ya estaba marcado, desde la dictadura militar (1964-1985), por una amplia variedad de experiencias y reformas, las cuales tuvieron como uno de sus resultados más importantes la universalización del acceso a la escolaridad obligatoria, a finales de la década de los años 90. Una vez resuelta la cuestión cuantitativa, el gran problema que quedaba fue el de la calidad de la enseñanza ofrecida en la escuela pública. A pesar de la situación privilegiada de São Carlos, situada en una de las regiones económicamente más ricas del país y con una fuerte tradición educativa, nuestras investigaciones nos llevan a afirmar que la primera gestión del PT en la ciudad debería haber materializado una política educativa más eficaz de la que fue implementada, con el fin de mejorar la calidad de la enseñanza ofrecida a la población.

Palabras clave: Política educativa. Partido de los Trabajadores.

Democratización de la educación.

\section{Introdução}

Este artigo tem como objeto de estudo a política educacional do primeiro governo do Partido dos Trabalhadores (PT) no municipio de São Carlos (SP), entre os anos de 2001 e 2004. Tal gestão realizou-se num contexto no qual as políticas educacionais brasileiras já haviam passado por um conjunto de mudanças desde 0 fim da ditadura militar (1964-1985). Marcadas de forma irremediável pelas combi- 
nações que se estabeleceram entre os dois marcos reformatórios de 1968 (universitário) e 1971 (ensino de $1^{\circ}$ e $2^{\circ}$ graus), particularmente em função das 8 séries obrigatórias do antigo $1^{\circ}$ grau e a formação de professores no âmbito dos cursos de licenciatura do ensino superior, o campo educacional brasileiro, mesmo depois de promulgada a chamada "Constituição cidadã" (1988), continuou condicionado pelas politicas engendradas durante os governos dos generais-presidentes.

Podemos identificar, grosso modo, quatro movimentos que guardavam, de uma forma ou de outra, vínculos com as reformas que foram impostas ao campo educacional durante a ditadura militar:

a) as experiências que ocorreram depois das eleições municipais de 1976, com a vitória de candidatos do Movimento Democrático Brasileiro (MDB) em muitas cidades do pais. Esses governos produziram políticas que questionavam, residualmente, a ideologia tecnicista que grassava no sistema nacional de educação gerado pela ditadura militar. Típicos foram os casos das cidades de Piracicaba (SP), Lages (SC) e Boa Esperança (ES), que desenvolveram medidas de ampliação e democratização da participação popular nas decisões educacionais e adotaram políticas pedagógicas com o intuito de melhorar a qualidade do ensino das escolas municipais';

b) as eleições diretas de governadores ocorridas em 1982 constituíram-se num dos marcos da transição entre a ditadura militar e o Estado democrático de direito, nas quais as oposições ganharam em vários estados da Federação. 0 Partido Democrático Trabalhista (PDT) venceu no Rio de Janeiro e o PMDB em nove estados, dentre os quais São Paulo, Minas Gerais, Paraná e Mato Grosso do Sul. Esses governos estaduais de oposição ao regime militar implementaram propostas educacionais que, em geral, representaram uma ruptura com a política dos governos militares, pautando-se pela "ênfase no ensino público e a democratização da educação [particularmente no âmbito da gestão da escola pública], no sentido de fazê-la acessivel e de boa qualidade para as crianças e os jovens das classes populares" (CUNHA, 2001, p. 108)2;

c) após o fim da ditadura militar, em 1985, abriu-se uma fase de ampla mobilização da comunidade educacional brasileira em torno dos debates travados durante 0 processo de elaboração e promulgação da Carta de 1988 (BRASIL, 1998). A materialização desse movimento ficou consubstanciada nos artigos que a Constituição consagrou à educação. Apesar de manter a coabitação do duplo sistema de ensino público e privado, os preceitos constitucionais referentes à educação avançaram. Podemos destacar, entre eles, os seguintes: o acesso ao ensino obrigatório e gratuito e considerado direito público subjetivo, a progressiva extensão da obrigatoriedade e gratuidade

\footnotetext{
Sobre as experiências educacionais desenvolvidas nos municipios oposicionistas após as eleições de 1976, consultar Cunha (2001).

2 A respeito das políticas educacionais adotadas pelos governos estaduais de oposição eleitos em 1982, mais uma vez digno de nota é Cunha (2001).
} 
do ensino médio, o atendimento educacional especializado para os portadores de deficiência, o ensino noturno regular e adequado às condições do educando, 0 atendimento em creche e pré-escola às crianças de 0 a 6 anos os quais foram considerados conteúdos mínimos para o ensino fundamental e gestão democrática do ensino público (BRASIL, 1998, Art. 206, Art. 208). Portanto, mesmo com o texto constitucional destinando recursos públicos para a iniciativa privada, os parlamentares progressistas, os movimentos sociais e os educadores conseguiram deixar sua marca em defesa da escola pública no texto constitucional (BRASIL, 1998, Art. 213);

d) depois, no transcurso da década de 1990, com o avanço ideológico das teses programáticas neoliberais, decorrente da conjuntura internacional marcada pelo fim do chamado "socialismo real" e da reestruturação produtiva das relações capitalistas de produção, o Estado brasileiro sofreu um contíguo processo de reformas ${ }^{3}$ que repercutiram também no campo educacional. Foi neste contexto que se inseriram a aprovação da nova Lei de Diretrizes e Bases da Educação Nacional (BRASIL, 1996) ${ }^{4}$, a aprovação do Fundo de Manutenção e Desenvolvimento do Ensino Fundamental e de Valorização do Magistério (FUNDEF) por meio da Lei 9424/96, a adoção dos Parâmetros Curriculares Nacionais (PCNs) de 1997, a reforma do ensino profissional por meio do Decreto n. ${ }^{\circ} 2.208 / 97$ (que regulamentou o $§ 2^{\circ}$ do Art. 36 e dos Arts. 39 a 42 da LDB/96) e a implantação de um sistema nacional de avaliação da educação básica e superior - a versão que o Sistema Nacional de Avaliação da Educação Básica (SAEB) assumiu após 1995, o Exame Nacional do Ensino Médio (ENEM), o Exame Nacional de Cursos (Provão) e a reestruturação do modelo de avaliação da pós-graduação estabelecido no âmbito da CAPES a partir do final dos anos 1990.

Em sintese: quando a primeira administração petista de São Carlos assumiu o poder municipal em 2001, o contexto histórico brasileiro já estava marcado, desde o final da ditadura militar (1985), por uma ampla gama de experiências e reformas no âmbito do seu sistema nacional de educação. Neste sentido, chamam a atenção, em particular, aquelas que passaram a regular o então ensino obrigatório de oito anos, ou seja, o ensino fundamental que ficou, pela Carta de 1988 (BRASIL, 1998, Art. 211), prioritariamente a cargo dos municípios. Portanto, se considerarmos que a questão educacional de caráter quantitativo, isto é, a demanda existente de matrículas para o contingente de crianças na idade de 7 aos 14 anos, havia sido resolvida, de certa forma, já no final da última década do século $X X$, e que o grande problema a ser enfrentado era o da qualidade do ensino ofertado no âmbito da escola pública, nossas pesquisas nos levam a afirmar que a primeira gestão petista de São Carlos teria de ter materializado uma política educacional mais efetiva do que aquela implementada.

\footnotetext{
Para se compreender a dimensão neoliberal que a reforma do Estado brasileiro assumiu na década de 1990, consultar: Pereira (1998) e Nogueira (2004).

4 Até dezembro de 1996 o ensino fundamental (antigo $1^{\circ}$ grau) esteve estruturado de acordo com os preceitos estabelecidos pela Lei Federal n. 5.692, de 11 de agosto de 1971.
} 
A experiência brasileira acumulada historicamente, desde 1971, referência cronológica que inaugura a expansão acelerada da escolaridade obrigatória de 8 anos, já apontava no início do primeiro decênio do século XXI para um programa educacional assentado nos seguintes paradigmas:

a) escola pública de tempo integral, com arquitetura adequada para atender às múltiplas atividades pedagógicas, recreativas, esportivas e administrativas que tal escola demanda ${ }^{5}$;

b) jornada integral de trabalho dos professores de 40 horas semanais, isto é, concentrada numa mesma escola e distribuída da seguinte forma: 50\% para as aulas e o tempo restante destinado às demais atividades pedagógicas. Pois, segundo Dermeval Saviani (2007, p. 1250), com a jornada única:

os professores poderiam participar da gestão da escola; da elaboração do projeto político-pedagógico da escola; das reuniões de colegiado; do atendimento às demandas da comunidade e, principalmente, além da preparação das aulas e correção de trabalhos, estariam acompanhando os alunos, orientando-os em seus estudos e realizando atividades de reforço para aqueles que necessitassem;

c) estatuto do magistério e política salarial que possibilite a ascensão e a progressão na carreira, com o objetivo de se alcançar uma efetiva valorização social do professor tanto do ponto de vista material quanto espiritual ${ }^{6}$;

d) a adoção de politica de formação continuada para os professores, com o intuito de se obter tanto a atualização didático-pedagógica como os conhecimentos, particularmente dos chamados saberes canônicos das disciplinas, que são objeto cotidiano do seu ofício. Ou como afirma Freitas $(2002$, p. 148) "a formação continuada é uma das dimensões importantes para a materialização de uma política global para o profissional da educação, articulada à formação inicial e a condições de trabalho, salário e carreira"7.

Em linhas gerais, essas são as medidas educacionais que deveriam ser implementadas, depois de quase 40 anos de expansão quantitativa da escola pública, no âmbito dos sistemas municipais de ensino fundamental, cujo escopo é a melhoria da qualidade do ensino público.

Sobre os pressupostos pedagógicos da escola pública de período integral, examinar Maurício (2009).

Segundo Pinto (2009), o salário médio do professor da escola pública, com jornada de 40 horas semanais, deveria ser de R\$ $2.500,00 /$ mês.

7 Sobre a história da política de formação de professores no Brasil, outras referências dignas de nota são: Saviani (2009), Freitas (2003) e Ferreira Júnior e Bittar (2006). 
No caso do municipio de São Carlos, podemos indicar, pelo menos, três características que o levaria a implementar tal programa educacional indicado acima. Eilas: está situado numa das regiões economicamente mais ricas do pais ${ }^{8} ;$ possui uma histórica tradição educacional: uma escola normal que começou a funcionar em 1911, uma escola técnica inaugurada em 1932, um campus da Universidade de São Paulo (USP), criado em 1954 e a Universidade federal de São Carlos (UFSCar), fundada em 1970; e passou a ser governado por um partido de esquerda que tem nas políticas públicas sociais uma das suas grandes bandeiras programáticas. Assim sendo, uma questão se impõe: teria a primeira administração petista de São Carlos implementado uma política pública que atendesse às demandas educacionais reivindicadas pelos contingentes populares dos seus habitantes ${ }^{9}$ ?

Vamos, então, para os resultados da pesquisa, que teve como fonte principal documentos oficiais da Prefeitura Municipal de São Carlos e da Secretaria Municipal de Educação e Cultura (SMEC), como leis e decretos, além de artigos de jornal. Os dados foram organizados conforme as cinco diretrizes do programa do PT para a educação em São Carlos na gestão 2001-2004 (PARTIDO DOS TRABALHADORES, 2001). São elas: democratização do acesso, democratização da gestão, melhoria da qualidade de ensino, educação de jovens e adultos e educação inclusiva.

\section{Democratização do acesso}

Em 2001, quando o PT assumiu a administração municipal em São Carlos (SP), herdou dos governos anteriores uma rede escolar que contava com 8 Escolas Municipais de Educação Básica (EMEBs), 24 Escolas Municipais de Educação Infantil (EMEls) e 11 creches municipais. Tal quadro possibilitava uma boa participação da rede pública municipal na oferta de educação infantil, contemplando, no ano 2000, quase $90 \%$ das matrículas nesse nível de ensino. No entanto, ainda havia grande déficit de vagas, sobretudo para crianças de 0 a 3 anos. 0 ensino obrigatório encontravase universalizado, com ampla cobertura da rede pública (estadual e municipal), embora o município contasse com uma rede pequena, responsável por somente 14\% das matrículas nesse nível de ensino (SILVA, 2009).

Vale ressaltar que a rede de escolas municipais de ensino fundamental em São Carlos era recente. Após a criação do FUNDEF, em 1996, os municípios se viram compelidos a ampliar sua participação nesse nível de ensino a fim de receber recursos do Fundo. Em São Carlos, a gestão 1996-2000, do Partido da Frente Liberal (PFL), não aderiu ao programa de municipalização do ensino fundamental incentivado pelo Governo Estadual do PSDB e optou pela criação de uma rede própria de escolas de ensino fundamental, acrescentando seis EMEBs às duas já existentes.

\footnotetext{
8 O município de São Carlos abriga, por exemplo, cinco das maiores empresas do Brasil: Volkswagen, Electrolux, Faber-Castell, TAM e Empresa Brasileira de Pesquisa Agropecuária (Embrapa).

9 Segundo o IBGE, o município de São Carlos possuía uma população de 192.998 habitantes no ano 2000.
} 
A gestão petista permaneceu contrária ao processo de municipalização do ensino, realizando poucos investimentos na expansão da estrutura física da rede de ensino fundamental. No período, apenas duas EMEBs foram ampliadas com a construção de novas salas de aula. Apesar dessa resistência, o município se viu pressionado a ampliar sua participação na oferta da escolaridade obrigatória, passando a atender quase $20 \%$ das matrículas iniciais em 2004. Uma possível explicação para esse fato é a política de fechamento de vagas na rede estadual, sobretudo nas primeiras séries do ensino fundamental, que vem ocorrendo desde a década de 90 e diminuindo a participação da rede estadual paulista na oferta de vagas para a escolaridade obrigatória.

Diante desse quadro, o governo do PT elegeu como uma de suas prioridades a democratização do acesso à educação infantil. Para tanto, a SMEC lançou mão de duas estratégias principais: investiu na construção e na ampliação de creches e EMEls, sobretudo nas áreas periféricas da cidade, ao mesmo tempo em que estabeleceu convênios com entidades filantrópicas para o atendimento às crianças pequenas.

Além das duas creches municipais herdadas do governo anterior já em fase final de construção, foram inaugurados dois Centros Municipais de Educação Infantil (CEMEIs), ampliadas várias EMEls e abertas mais três (em casas alugadas e adaptadas). Esses dados demonstram uma expansão modesta da rede física. Segundo dados do Censo Escolar do MEC (INEP, 2007) e da Fundação SEADE (SÃO PAULO, 2003), ao longo do período, a expansão das matrículas foi maior nas creches, chegando a quase dobrar entre 2001 e 2004, mas a participação da rede municipal permaneceu baixa em relação à rede particular, contemplando apenas 58,64\% das matrículas no último ano da gestão. Na pré-escola, o aumento do número de matrículas não chegou a 270 crianças, observando-se no periodo uma queda na taxa de participação da rede pública no atendimento desse nível de ensino em relação à rede privada, caindo de 89,41\% em 2001, para 85,78\% em 2004 (SILVA, 2009).

0 caminho encontrado, então, pelo governo petista para ampliar o atendimento na educação infantil foi a celebração de convênios entre a Prefeitura Municipal e creches filantrópicas da cidade. Na ata da sessão da Câmara Municipal em que a lei autorizando os convênios foi aprovada por unanimidade, alguns vereadores destacaram o caráter paliativo dessa iniciativa. Uma vereadora do PT afirmou que, "Apesar de não resolver o problema, o presente projeto demonstra o empenho e a vontade do Governo em estar resolvendo (sic) as questões pertinentes à demanda e quantidade de creches e Emeis existente" (SÃO CARLOS, 2001a, grifo nosso). Já a Presidente da Comissão de Educação da Câmara na época, vereadora do PMDB, foi mais enfática: "É uma solução paliativa fazer convênio? É. Qual é o ideal? Que o Poder Público possa atender diretamente todas as crianças, mas é um caminho de solução" (SÃO CARLOS, 2001a). 
Na ocasião da celebração dos convênios, em fevereiro de 2002, o Prefeito ressaltou que "as entidades filantrópicas desenvolvem uma atividade importante, pois permitem uma complementação do trabalho do poder público" (NEWTON..., 2002, p. A3, grifo nosso). Nota-se nesta afirmação que a medida baseou-se na concepção neoliberal de que o Estado precisa compartilhar com a iniciativa privada a responsabilidade pela garantia do direito à educação ${ }^{10}$, embora tal garantia seja, constitucionalmente, um dever estatal.

A Lei Municipal $n^{\circ} 12.917$ (SÃO CARLOS, 2001b), aprovada com o objetivo de ampliar o número de vagas oferecidas às crianças com idade entre 3 meses e 6 anos, previa o comprometimento do Poder Público em fornecer: cursos de capacitação profissional aos educadores das creches filantrópicas em igualdade de condições aos oferecidos aos profissionais da rede municipal de ensino; gêneros alimentícios às crianças atendidas pelas entidades; repasse mensal no valor de $\mathrm{R} \$ 20,00$ (vinte reais) por criança atendida pela entidade. Com a subvenção da Prefeitura, essas entidades, que antes atendiam 540 crianças, passaram a ter capacidade para atender 800 .

Com a garantia de participação nos cursos de capacitação oferecidos pela SMEC, havia o objetivo de assegurar um processo de unificação pedagógica envolvendo as EMEls, creches municipais e filantrópicas, a fim de se atingir um padrão unificado de qualidade na educação infantil. No entanto, o padrão de qualidade almejado mostra-se incompativel com os valores extremamente baixos repassados às entidades filantrópicas, apesar dos reajustes anuais. Assim, em julho de 2002 o repasse foi estipulado em $R \$ 30,00$ (trinta reais) mensais por criança atendida pela entidade conveniada. Em setembro de 2003, houve uma alteração na forma de distribuição do repasse: estipulou-se o valor de $\mathrm{R} \$ 33,00$ (trinta e três reais) mensais por cada criança atendida em regime integral, e $R \$ 16,50$ (dezesseis reais e cinquenta centavos) mensais por criança atendida em regime de meio-período. Em agosto de 2004, o valor subiu para $\mathrm{R} \$ 40,00$ (quarenta reais) por mês por criança atendida em regime integral, e $R \$ 20,00$ (vinte reais) mensais por aquelas atendidas em regime de meio-período.

Ainda com relação à democratização do acesso à educação, cabe registrar a ação da Prefeitura no fornecimento de merenda escolar a todas as escolas públicas do município, em virtude de um convênio com o governo do Estado, e a distribuição anual de material e uniforme escolar para os alunos da rede municipal. Além disso, nessa primeira gestão petista houve a abertura de concursos públicos para a contratação de profissionais da educação infantil, do ensino fundamental e da educação de jovens e adultos.

10 Sobre a concepção neoliberal da educação, consultar: Friedman (1984). 


\section{Democratização da gestão}

As ações da administração petista em São Carlos voltaram-se para a ampliação dos canais de participação de professores, funcionários, pais de alunos e alunos na gestão da escola municipal. Visando a estimular o debate sobre a política educacional do município, foram instituídas as Conferências Municipais de Educação de São Carlos. Ao longo da gestão 2001-2004 ocorreram duas conferências versando sobre os seguintes temas: Democratização da Gestão e Democratização do acesso e permanência.

A nova gestão logo anunciou mudanças na forma de contratação dos diretores das escolas municipais, o que passaria a ser feito por meio de eleição. Lembramos que, até aquele momento, o provimento desse cargo era decisão exclusiva do Poder Executivo. As eleições para diretores das 11 creches municipais ocorreram já no início da gestão petista, em janeiro de 2001. No edital publicado pelo Secretário Municipal de Educação e Cultura, exigia-se que os candidatos preenchessem três requisitos: possuir licenciatura plena em Pedagogia ou pós-graduação em Educação; ser funcionário público concursado, estar em efetivo exercício na Prefeitura Municipal de São Carlos e ter experiência de, pelo menos, dois anos no magistério público (SÃO CARLOS, 2001c).

Além disso, os candidatos deveriam entregar um Plano de Trabalho que contemplasse diagnóstico da unidade escolar, proposta de ação e de avaliação. Eles tiveram apenas cinco dias, entre a publicação do edital (SÃO CARLOS, 2001c) e o fim das inscrições, no dia 8 do mesmo mês, para elaborar seu plano de trabalho. A apresentação desses planos pelos próprios candidatos, nas unidades de interesse, para debate aberto com funcionários, usuários e comunidade foi realizada nos dias 9 e 10 de janeiro, e as eleições nos dias 11 e 12 . Tiveram direito a voto apenas os profissionais lotados nas creches, ou seja, a comunidade usuária não pôde votar.

Para esse processo eleitoral, foi estabelecido que os três candidatos mais votados deveriam compor uma lista triplice a ser encaminhada ao Prefeito Municipal, o qual escolheria, dentre os três nomes, o novo diretor. Sobre esse aspecto, o edital deixava claro que "O provimento do cargo, nos termos da legislação em vigor, é prerrogativa e competência do Prefeito Municipal, que procederá à escolha de cada diretor(a) e à respectiva nomeação" (SÃO CARLOS, 2001c).

A partir das listas tríplices, o Prefeito escolheu e nomeou as novas diretoras das creches municipais. Com base nessa primeira experiência, teve início a preparação do processo eleitoral para escolha de diretores nas demais escolas da rede municipal. Assim, no dia 8 de março do mesmo ano a SMEC publicou a Portaria 003/01, instituindo o processo eleitoral, por meio da composição de listas tríplices, para diretores das 31 Escolas Municipais de Educação Infantil e de Educação Básica de São Carlos (SÃO CARLOS, 2001d). 
Nesse novo processo eleitoral, mantiveram-se os mesmos requisitos para os candidatos e a apresentação do plano de trabalho. Em cada escola foi criada uma Comissão Eleitoral, composta por dois pais de alunos, dois professores e um funcionário, a qual ficou responsável pelo encaminhamento do processo. Diferentemente do que ocorreu nas creches, dessa vez foi permitido que a comunidade usuária participasse da eleição. Além dos profissionais da unidade escolar, tiveram direito a voto todos os alunos com idade acima de 16 anos, bem como os pais de alunos que, independentemente do número de filhos matriculados, tiveram direito a um voto por família. Estabeleceu-se ainda o caráter paritário da eleição entre comunidade usuária e profissionais da unidade, na proporção de 50\% para cada setor no cômputo dos votos. Algumas escolas tiveram candidato único, enquanto em outras, havia de dois a quatro, perfazendo um total de 63 candidatos.

A partir da votação foram compostas as listas tríplices encaminhadas à apreciação do Prefeito. A Diretora de Educação na época apontou algumas das razões que levaram a Secretaria a manter o recurso das listas tríplices em detrimento da proposta de eleição direta, considerada, inclusive pelos petistas, mais democrática na medida em que nela prevalece a vontade da maioria. Segundo ela, "nós tínhamos um receio de que as pessoas que claramente boicotavam nosso trabalho pudessem candidatar-se e pudessem ser eleitas. Esse era um problema naquele momento" (PALHARES; MARINS, 2002 apud SOUZA, 2006, p. 136). Além disso, havia denúncias de má gestão do dinheiro público na rede que ainda seriam investigadas, e a lista triplice seria uma forma de impedir que pessoas comprovadamente envolvidas com irregularidades assumissem o cargo de direção. Observa-se assim que, por meio da lista tríplice, o PT visava a manter o processo eleitoral de dirigentes escolares sob seu controle.

0 Prefeito acabou optando, em quase todos os casos, pelo candidato mais votado. Das 31 unidades escolares que participaram do processo, em 27 permaneceram os mesmos diretores, havendo pouca renovação dos quadros de direção das escolas municipais. Segundo Souza (2006), um dos fatores que podem ter contribuído para esse fato foi a baixa participação dos eleitores durante os debates. De um total de 7.600 pessoas que votaram nessas eleições, estiveram presentes nas discussões dos planos de trabalho apenas 2.000. Com isso, "a maioria não chegou a conhecer as propostas apresentadas pelos candidatos" (SOUZA, 2006, p. 66), o que levou muitos a optar pelo diretor em exercício, cujo trabalho já era conhecido.

O Secretário Municipal de Educação e Cultura destacou três pontos importantes da iniciativa:

Primeiro que as eleições negam uma perspectiva de trabalho cujo caráter era de clientelismo. Em segundo lugar, o projeto apresentado pelo candidato apresenta uma perspectiva de 
legitimidade local, inclusive do ponto de vista pedagógico. Em terceiro lugar, não basta apenas a eleição, mas todo o modelo de gestão existente deverá ser reformulado. Estas eleições são apenas o início de um processo que deverá criar, inclusive, um novo estatuto (PREFEITURA..., 2002, p. A3).

Estava presente, portanto, a preocupação de articular o processo de eleição dos dirigentes escolares com outras medidas importantes da gestão democrática, tais como a criação dos Conselhos de Escola. Também já havia a preocupação em formalizar tais canais e processos participativos no Estatuto do Magistério Municipal, cuja reformulação seria iniciada ainda na primeira gestão petista.

Sobre essa questão, é importante ressaltar que os próprios defensores da eleição para diretores escolares reconhecem que tal processo, por si só, não é capaz de eliminar os padrões clientelistas e autoritários da gestão educacional. Segundo Paro (2003, p. 99-100),

Obviamente, as pessoas que pensavam que, com as eleições, o diretor mudaria seu comportamento de forma radical e imediata frustraram-se ao perceber que muito das características do chefe monocrático que detém a autoridade máxima na escola persistiu mesmo com a eleição. Mas o que isso reafirma é que as causas do autoritarismo existente nas unidades escolares não advêm exclusivamente do provimento do diretor pela via da nomeação política. Antes, é preciso considerar que tal autoritarismo é resultado da conjunção de uma série de determinantes internos e externos à unidade escolar, que se sintetizam na forma como se estrutura a própria escola e no tipo de relações que aí têm lugar. Por isso, mais uma vez é preciso ter presente que, também neste caso, não se trata em absoluto de culpar a eleição, mas de reconhecer que ela tem limites que só podem ser superados quando se conjugarem ao processo eletivo outras medidas que toquem na própria organização do trabalho e na distribuição da autoridade e do poder na escola.

No entanto, a experiência da eleição de diretores em São Carlos não teve tempo de ser amadurecida e acabou abandonada pelo próprio governo do PT. No final da primeira gestão, em dezembro de 2004, foi aprovada a Lei $n^{\circ} 13.486$, que dispõe sobre a organização administrativa da Prefeitura Municipal de São Carlos. Nela, a direção das escolas municipais foi caracterizada como função gratificada, desempenhada por servidor público efetivo "mediante designação do Prefeito Municipal" (SÃO CARLOS, 2004b, Art. 24). 0 diretor voltou, assim, a ser indicado pelo Poder Executivo. 
Uma das questões que parece mais ter pesado na decisão de se retornar à forma de indicação foi a pouca renovação do quadro de diretores, o que contrariou as expectativas da administração municipal. É o que se pode concluir do seguinte depoimento do próprio Prefeito a respeito da experiência de eleição de dirigentes realizada em sua gestão:

Existe a concepção de que democracia pressupõe, entre outros elementos, eleições diretas. Estamos de acordo com isso. Entretanto, para que o processo seja legítimo, é preciso que seja garantida a igualdade de condições entre todos os concorrentes. Em nossa visão, isto não aconteceu no processo realizado em 2001, pois não previu afastamento dos que já ocupavam cargo de direção (cargos de confiança indicados pelo governo anterior, derrotado nas eleições). Isto, associado à ausência da cultura de participação, expressão de opiniões e construção coletiva de propostas, ficou evidente que existiram espaços para o exercício, consciente ou não, de manipulação de opiniões. 0 resultado foi que praticamente $100 \%$ dos que já estavam no cargo se elegeram (LIMA NETO apud SOUZA, 2006, p. 135).

Nota-se, aqui, uma contradição: apesar de constatar a ausência da cultura de participação como um dos principais problemas ocorridos no processo eleitoral, o governo do PT optou justamente por abandonar uma prática que tem o potencial de contribuir para a construção de um ambiente mais democrático e aberto à participação de todos. 0 procedimento da indicação do diretor escolar ficou posteriormente consolidado no próprio Estatuto da Educação Municipal de São Carlos, aprovado em 2006, durante a segunda gestão petista na cidade.

Conforme afirmamos, o processo de eleição dos diretores das escolas municipais promovido pela SMEC estava ligado à preocupação de criar canais de participação dos profissionais e da comunidade usuária nas decisões escolares. Foi nesse sentido que a Secretaria se mobilizou para fortalecer os Conselhos de Escola em toda a rede municipal. Ao longo do ano de 2002 a SMEC procurou mobilizar pais, professores e funcionários em torno dessa questão, promovendo palestras e campanhas sobre a importância da participação nos Conselhos Escolares. Tal mobilização resultou no Decreto $n^{\circ} 11$ (SÃO CARLOS, 2003a), que instituiu o Conselho de Escola em todas as creches, EMEls e EMEBs da rede municipal de ensino de São Carlos.

Observa-se nesse decreto a preocupação em criar um conselho representativo de todos os segmentos da comunidade escolar, bem como capaz de intervir diretamente na gestão da escola. Isso fica explícito no Art. $2^{\circ}$, o qual estabelece que:

A gestão da escola será desenvolvida de modo coletivo, envolvendo toda a comunidade escolar, sendo o Conselho 
de Escola a instância de elaboração, deliberação, acompanhamento, fiscalização e avaliação do planejamento e do funcionamento da unidade escolar (SÃO CARLOS, 2003a).

Já o Art. $6^{\circ}$ esclarece quanto às funções que o Conselho de Escola deve desempenhar:

0 Conselho de Escola terá funções consultiva, deliberativa e fiscalizadora, cabendo-Ihe estabelecer, para o âmbito da escola, diretrizes e critérios gerais relativos à sua ação, organização, funcionamento e relacionamento com a comunidade, compatíveis com as orientações e a Política Educacional da Secretaria Municipal de Educação e Cultura, participando e responsabilizando-se social e coletivamente pela implementação de suas deliberações (SÃO CARLOS, 2003a).

0 Conselho Escolar, assim, além de deliberar sobre as necessidades da escola, é também responsável pela implementação de suas deliberações, o que the confere grande força política. Para garantir a representatividade de todos os setores da comunidade escolar no Conselho, o decreto estabelece os critérios de paridade e proporcionalidade, "de tal forma que a soma dos representantes da equipe escolar seja igual ao número de representantes da comunidade usuária" (SÃO CARLOS, 2003a). Outro aspecto importante da distribuição do poder dentro do Conselho de Escola é a determinação de que o diretor da escola, embora membro nato, não pode ser eleito presidente do Conselho.

Todos os conselheiros devem ser eleitos em assembleia por seus pares. A primeira eleição ocorreu logo em abril de 2003, em cada uma das unidades de ensino da rede municipal. Na época, foram eleitos e empossados 970 conselheiros, entre titulares e suplentes, que tiveram mandato de um ano com possibilidade de reeleição. Com a instituição desses novos Conselhos de Escola, é possivel afirmar que houve empenho da administração petista para criar uma estrutura que possibilitasse a democratização da gestão no interior das escolas. Resta saber em que medida tal estrutura tem sido utilizada de forma a cumprir o objetivo a que se propõe.

\section{Melhoria da qualidade de ensino}

0 programa do PT para São Carlos (PARTIDO DOS TRABALHADORES, 2001) destacava como forma de melhorar a qualidade do ensino desenvolvido na rede municipal, tanto a modernização das estruturas escolares como a valorização dos profissionais da educação, mediante formação continuada e plano de carreira do magistério. Este último ponto acabou levando às discussões para a reformulação do Estatuto do Magistério Público Municipal vigente. 
Consoante ao objetivo de "Modernizar as estruturas escolares, oferecendo condições materiais para o desenvolvimento dos educandos" (PARTIDO DOS TRABALHADORES, 2001, p. 4), a SMEC lançou o projeto das Escolas do Futuro, que previa a construção de um prédio contíguo a todas as EMEBs da rede, onde funcionariam uma biblioteca e um laboratório de informática. Na concepção do projeto foram observados os seguintes aspectos: uso de cor nos elementos arquitetônicos; conforto ambiental (acústico, térmico e de luminosidade); livre acesso ao acervo bibliográfico; sala multiuso para reuniões, cursos, palestras, oficinas; pátio externo integrado com mesas e bancos para leitura ao ar livre e jogos; facilidade de acesso aos portadores de deficiências físicas; uma porta para a escola e outra para a comunidade (ESCOLA..., 2002, p. A3). Até o final da primeira gestão petista, seis prédios foram inaugurados e outros dois estavam em construção.

Como parte integrante desse projeto, todas as EMEBs foram contempladas com laboratórios de informática equipados com computadores e impressoras. Por meio desses laboratórios, a expectativa da SMEC era promover a "alfabetização digital" de todos os alunos da rede municipal (PREFEITURA..., 2002, p. A4).

A estrutura das escolas de educação infantil também foi alvo de investimentos da Prefeitura, que adquiriu livros, brinquedos, materiais lúdico-pedagógicos, aparelhos de som e CDs para creches e EMEls. Além disso, houve reformas das unidades escolares, com ampliação de pátios e adequação dos sanitários às crianças pequenas.

Diversos foram os programas e cursos de formação oferecidos aos profissionais da educação infantil e do ensino fundamental da rede municipal de São Carlos, ao longo da primeira gestão do PT. Destacamos alguns deles:

a) Em 2001 foi celebrado convênio entre o Poder Executivo Municipal e a União, por intermédio do Ministério da Educação, para a implantação do Programa de Formação de Professores Alfabetizadores (PROFA) em São Carlos. Voltado especialmente para os professores de $1^{\text {a }}$ e $2^{\text {a }}$ séries do ensino fundamental, o programa tinha por objetivo apresentar alternativas ao professor no processo de ensino e aprendizagem.

b) Outra ação voltada para a melhoria da aprendizagem de leitura e escrita entre os alunos das séries iniciais do ensino fundamental foi o projeto "Estudar pra Valer!", fruto de uma parceria entre a SMEC, a Fundação Volkswagen e o Centro de Estudos e Pesquisas em Educação, Cultura e Ação Comunitária (CENPEC). 0 programa foi desenvolvido entre os anos de 2003 e 2004 em três EMEBs. Ao todo, foram envolvidos mais de 2 mil alunos da $1^{\text {a }}$ à $4^{\text {a }}$ série, além de cerca de 60 professores que participaram de cursos de formação continuada. A metodologia do projeto foi desenvolvida pelo CENPEC, que busca trabalhar conteúdos de leitura e escrita em relação aos diferentes gêneros, oferecendo material de apoio impresso para todos os alunos. 
c) Em 2002 a SMEC lançou, em parceria com o Instituto Ciência Hoje da Sociedade Brasileira para o Progresso da Ciência (SBPC), o "Programa Ciência Hoje de Apoio à Educação", com o objetivo de investir na melhoria da qualidade do ensino de ciências na rede municipal. Visando a atender alunos de $3^{\mathrm{a}}$ e $4^{\mathrm{a}}$ séries do ensino fundamental, 0 programa promoveu a capacitação dos professores para trabalhar com a revista "Ciência Hoje das Crianças" como ferramenta didática que ressalta a utilização prática da ciência. A formação buscou fortalecer a prática de trabalhar com projetos, elaborando coletivamente propostas de aprendizagem ativas, cooperativas e interdisciplinares.

d) Antecipando-se à Lei Federal n 10.639 , de janeiro de 2003, que tornou obrigatório o ensino sobre História e Cultura Afro-Brasileira nos estabelecimentos de ensino fundamental e médio oficiais e particulares de todo o país, a SMEC de São Carlos já trabalhava, desde 2001, com essa temática na rede municipal. Durante a primeira gestão, a área de Educação Étnica da SMEC realizou, em parceria com diversas instituições, vários cursos de capacitação e oficinas temáticas para os profissionais da rede.

e) Visando a elevar o nível de qualificação dos professores municipais, em junho de 2003 foi aprovada a Lei no 13.175 (SÃO CARLOS, 2003b), autorizando o Poder Executivo a celebrar convênio de cooperação técnica com instituições de ensino, públicas ou privadas, para formação em nivel superior dos professores e pajens concursados em exercício nos diversos níveis de ensino da rede municipal. A lei previa o repasse às entidades conveniadas de um valor total máximo de $R \$$ $564.000,00$ (quinhentos e sessenta e quatro mil reais), em parcelas mensais e sucessivas, durante a vigência dos convênios. A assinatura do convênio entre a Prefeitura Municipal e a UNICEP, um centro universitário da cidade, ocorreu em agosto de 2003. Essa parceria previa a oferta do curso de Pedagogia aos professores da rede municipal interessados, que deveriam passar por exame de seleção. Se estivessem aptos a fazer o curso, as mensalidades seriam divididas entre a própria instituição, o Governo Municipal e o professor, cada uma das partes arcando com um custo mensal de $\mathrm{R} \$ 100,00$ (cem reais).

Sob esse mesmo tipo de inspiração, em junho de 2004 foi aprovada nova lei autorizando o Poder Executivo Municipal a celebrar convênio com Universidades, Centros Universitários e demais Instituições de Ensino Superior com o objetivo de efetivar cursos de capacitação e aperfeiçoamento dos profissionais da rede municipal de educação. 0 convênio consiste no pagamento pelo município de bolsa-auxílio, parcial ou integral, para cursos de extensão ou de pós-graduação, em nível de especialização. A lei toma o cuidado de declarar a despesa resultante do convênio como gasto no desenvolvimento do ensino (SÃO CARLOS, 2004a). Assim, com a conivência do governo petista, as instituições privadas garantiram para si novos repasses de verbas públicas, sob a alegação de investimento na melhoria da qualidade do ensino público da rede municipal. 
0 programa do PT para a educação em São Carlos já previa a necessidade de readequação do Estatuto do Magistério Público Municipal, que estava em vigor desde 1996, antes da aprovação da nova LDB e da criação do FUNDEF. Em decorrência disso, vários aspectos precisavam ser revistos, inclusive a necessidade de inclusão das creches e de seus profissionais na rede municipal de ensino.

Em 2002 a SMEC deu início à discussão do novo Estatuto da Educação Municipal. A mudança do nome foi justificada pela intenção de contemplar nesse estatuto não somente os professores, mas também todos os profissionais ligados à educação municipal, tais como inspetores de alunos, secretários de escola e merendeiras. Além disso, a Secretaria, juntamente com os vereadores da bancada do PT, buscavam a construção de um estatuto que regulamentasse não somente a carreira do magistério, mas também a estrutura e a organização da educação pública municipal.

Uma novidade desse estatuto foi o próprio processo de elaboração da lei. 0 Estatuto do Magistério, aprovado em 1996, foi elaborado por uma comissão de dez profissionais designados pelo Poder Executivo. 0 projeto elaborado por essa comissão foi aprovado pela Câmara Municipal, sem envolvimento direto dos profissionais da rede municipal de ensino. Para a revisão desse estatuto, a SMEC defendeu e estimulou a participação de todos os envolvidos no processo educacional: professores, diretores, coordenadores, inspetores, merendeiras e demais funcionários de creches, EMEls e EMEBs.

A proposta de construção coletiva do estatuto foi lançada em março de 2002, com a aprovação de um cronograma para as reuniões dos grupos de trabalho, abertas a todos os interessados. Os grupos deveriam discutir temas específicos do estatuto e elaborar relatórios finais que subsidiariam a confecção do projeto de lei.

A SMEC previa a regulamentação, pelo novo estatuto, de diversos aspectos da educação municipal, tais como: a entrada exclusiva por concurso público, a definição de quais cargos poderiam ser comissionados e quais eleitos; a carreira dos professores, atribuições de aulas, vencimentos, piso salarial e jornada de trabalho; a gestão democrática da educação.

Apesar da pressão dos vereadores para que o projeto de lei do estatuto fosse enviado logo à Câmara Municipal, a fim de que houvesse tempo para debatê-lo antes do ano eleitoral (2004), apenas no último ano da gestão a SMEC concluiu a elaboração do anteprojeto, procurando contemplar as sugestões efetuadas pelos profissionais da educação municipal durante as discussões sobre o estatuto. Nesse anteprojeto já haviam sido incorporadas questões importantes, como a valorização do profissional considerando sua formação e capacidade no desempenho da função. A proposta de eleição para diretores escolares já havia sido descartada, prevalecendo a forma de indicação pelo Prefeito Municipal. 
Esse anteprojeto foi apresentado primeiramente à rede de ensino municipal para a incorporação de novas sugestões. Somente depois disso o projeto final de estatuto seria enviado à Câmara Municipal, o que aconteceu apenas na segunda gestão do PT em São Carlos (2005-2008). A Lei $n^{\circ} 13.889$, que regulamentou o novo Estatuto da Educação Municipal, foi aprovada em outubro de 2006.

\section{Educação de jovens e adultos}

0 carro-chefe da política para a educação de pessoas adultas no governo petista foi o "Movimento de Alfabetização de Jovens e Adultos de São Carlos" (MOVA/São Carlos). 0 programa tinha como objetivo combater o elevado índice de analfabetismo no município, situação contraditória ostentada pela "Capital da Tecnologia". Segundo o Mapa do Analfabetismo no Brasil (INEP, 2003), publicação com dados relativos ao ano 2000, São Carlos possuía 22.933 analfabetos funcionais (pessoas com menos de quatro anos de estudo), o que correspondia a uma taxa de $15,6 \%$ da população.

Inspirado nas experiências de outras cidades governadas pelo PT que adotaram o MOVA - programa inicialmente criado na capital paulista quando Paulo Freire esteve à frente da Secretaria de Educação, na gestão 1989-1992 -, o MOVA/São Carlos foi inicialmente pensado como um movimento de caráter temporário visando a recuperar um atraso educacional. Para isso, o Poder Público buscaria o engajamento da sociedade civil, estabelecendo convênios com entidades e associações que indicariam educadores voluntários e/ou cederiam espaços e ofereceriam materiais básicos para a montagem de uma sala de alfabetização.

A Lei no 12.968 (SÃO CARLOS, 2002b), aprovada em março de 2002, determinou que o programa se realizaria com pessoal voluntário, que receberia bolsaauxilio. Os legisladores se preocuparam em exigir dos educadores uma capacitação mínima para o trabalho com alfabetização de adultos, determinando que estes atendessem a um dos seguintes requisitos: fossem formados ou estivessem cursando o curso de magistério ou de licenciatura. A formação inicial dos voluntários ocorreu em maio de 2002, e no mês seguinte cerca de 60 salas de alfabetização começaram a funcionar.

Em junho de 2003, a Prefeitura de São Carlos assinou convênio com o Governo Federal para o funcionamento do programa "Brasil Alfabetizado" no município, o qual passou a dividir espaço com o MOVA na área da educação de jovens e adultos. 0 curso de capacitação para os educadores, também voluntários, teve início em julho de 2003, sob a coordenação de profissionais da SMEC e de professores da UFSCar. Inicialmente foram abertas 35 salas do "Brasil Alfabetizado", as quais, assim como as salas do MOVA, começaram a funcionar em centros comunitários, igrejas e escolas que ainda não possuiam salas de alfabetização. 
Segundo dados da Prefeitura Municipal (SÃO CARLOS, 2004c, p. 29), em 2004 havia em São Carlos 41 salas do MOVA e 20 salas do "Brasil Alfabetizado". Os dois programas de alfabetização de pessoas jovens a adultas continuam em funcionamento no município. Apesar da expectativa da SMEC de que esses programas ampliassem a procura por cursos oficiais de EJA, os dados do Censo Escolar do MEC (INEP, 2007) apontam que, entre os anos de 2001 e 2004, houve uma pequena diminuição no número de matrículas nessa modalidade de ensino, caindo de 1478 em 2001, para 1405 no último ano da gestão.

É importante destacar que algumas características do MOVA causaram grande polêmica na época de sua discussão, tais como o seu caráter de movimento e a utilização de educadores voluntários. Durante a sessão da Câmara Municipal em que o projeto de lei foi aprovado, esses pontos do programa foram criticados por um vereador do PDT, o qual afirmou que "o Município pretende, com este projeto, terceirizar a educação com caráter de mobilização social, sem de fato assumir o compromisso com a educação e com os educadores" (SÃO CARLOS, 2002a). A crítica do vereador faz sentido se considerada dentro do contexto de reforma do Estado ${ }^{11}$ que o país vivenciou ao longo da década de 90, a qual impôs limitações reais ao investimento nas políticas sociais. Isso se manifestou de forma especialmente grave na educação de jovens e adultos, uma vez que, na lei que regulamentou o FUNDEF, foi vetado o inciso que mandava considerar também as matrículas do ensino fundamental nos cursos de EJA para a distribuição dos recursos do Fundo (ARELARO; KRUPPA, 2007). Desse modo, sem desconsiderar os resultados positivos no combate ao analfabetismo que o MOVA tem obtido em diversos municípios do país, cabe a pergunta se, na prática, esse movimento, baseado em parcerias do Estado com a sociedade civil e no trabalho voluntário, não seria uma forma barateada de permitir o acesso à educação para populações historicamente marginalizadas.

\section{Educação inclusiva}

A partir de 2001, as ações da SMEC na área de Educação Especial giraram em torno do programa "Escola Inclusiva". Inspirado na proposta do Partido dos TrabaIhadores, o programa "fundamenta-se nos princípios de educação para todos e defende que 0 atendimento a toda criança, jovem e adulto com necessidades especiais aconteça dentro do sistema regular de ensino, construindo, assim, uma sociedade inclusiva" (PALHARES; MARINS, 2002, p. 7).

Até o ano 2000, o atendimento na rede municipal de ensino de São Carlos se limitava a pessoas com deficiência visual e auditiva. Por isso, o "primeiro marco

11 A respeito da reforma que o Estado brasileiro sofreu a partir do primeiro governo do presidente Fernando Henrique Cardoso, examinar: PEREIRA, 1998, p. 22 Et seq. 
na gestão [petista] da educação inclusiva foi a garantia de vagas para os alunos com necessidades educacionais especiais, considerando qualquer tipo de deficiência" (PALHARES; MARINS, 2002, p. 7). Outro avanço foi a contratação de professores específicos para a Educação Especial, por meio de concurso público. 0 programa "Escola Inclusiva" ofereceu cursos, palestras e oficinas a todos os professores da rede municipal, buscando fornecer subsídios para a qualificação e o envolvimento desses profissionais na proposta de educação inclusiva. Além disso, a partir de 2002, a SMEC fez entregas de material para Educação Especial nas creches, EMEls e EMEBs do município.

0 esforço para ampliar o atendimento às pessoas com necessidades educacionais especiais se refletiu nos números do Censo Escolar do MEC (INEP, 2007). No ano 2000, houve 63 alunos matriculados na Educação Especial da rede municipal de São Carlos. Já em 2004, o número de alunos com necessidades educativas especiais matriculados na rede regular de ensino fundamental foi de 156, registrando um aumento de quase $150 \%$.

\section{Conclusão}

A partir da pesquisa realizada sobre a política educacional do primeiro governo petista de São Carlos, consideramos que os programas voltados para a alfabetização de jovens e adultos e para a educação inclusiva, assim como a ampliação dos canais de participação da comunidade escolar na gestão educacional, merecem destaque. No entanto, observamos que não foram realizadas medidas de impacto na democratização do acesso à escola, especialmente no âmbito da educação infantil, ou na melhoria da qualidade do ensino, áreas que necessitariam de mais investimentos do Estado.

É possivel verificar que algumas questões que vêm sendo consideradas fundamentais pela comunidade educacional para a construção de uma escola pública de qualidade - das quais destacamos a jornada única dos professores e a ampliação do tempo de permanência dos alunos na escola, articulada a um projeto educativo de tempo integral - não foram problemas enfrentados em São Carlos, o que nos leva a concluir que o Partido dos Trabalhadores poderia ter realizado muito mais ações no sentido de contribuir para a melhoria da qualidade do ensino público no municipio.

Apesar da hegemonia política do PT na cidade, que já está em sua terceira gestão e tem governado com base em um programa democrático, os números corroboram nossas conclusões. 0 último Índice Paulista de Responsabilidade Social (IPRS), publicado pela Fundação SEADE em março de 2009, indicou que São Carlos ocupa apenas a $377^{a}$ posição, entre os 645 municípios paulistas, no quesito escolaridade. Entretanto, no ano 2000, a cidade ocupava a 62a posição nesse mesmo quesito, ou seja, outros municípios, no período em que São Carlos era governado pelo PT, avançaram muito mais em termos educacionais. Neste sentido, o jornal "Primeira 
Página", que publicou os números levantados pela pesquisa do IPRS, apontou que os avanços educacionais da população são-carlense em idade escolar, no âmbito dos ensinos fundamental e médio, foram pouco significativos:

Em São Carlos a pesquisa mostra que a proporção de pessoas de 15 a 17 anos que concluíram o ensino fundamental variou de $67,4 \%$ para $66 \%$. 0 percentual de pessoas de 15 a 17 anos com pelo menos quatro anos de estudo aumentou de 93,1\% para 96,6\%. A proporção de pessoas de 18 a 19 com ensino médio variou de $38,60 \%$ para $39,4 \%$. Ainda de acordo com o levantamento do SEADE, a taxa de atendimento à pré-escola entre crianças de 5 a 6 anos, variou de $83,7 \%$ para $84,9 \%$ (SÃO Carlos fica em $377^{\circ}$ em escolaridade, 2009, p. B1).

Assim, podemos concluir que, apesar do discurso democrático presente na política educacional do governo do PT em São Carlos, a cidade continua não oferecendo ao conjunto de sua população uma escola pública que atenda plenamente aos seus interesses educacionais. Ostentando o título de "Capital da Tecnologia" e a maior concentração de doutores entre as cidades brasileiras, São Carlos ainda não conseguiu superar a contradição manifesta entre os nichos de excelência acadêmica das suas universidades (USP e UFSCar) e as escolas públicas destinadas às camadas populares dos seus cidadãos.

\section{Referências}

ARELARO, L. R. G.; KRUPPA, S. M. P. A educação de jovens e adultos. In: OLIVEIRA, R. P.; ADRIÃO, T. (Org.). Organização do ensino no Brasil: níveis e modalidades na Constituição Federal e na LDB. 2. ed. São Paulo: Xamã, 2007.

BRASIL. Constituição (1988). Constituição da República Federativa do Brasil: promulgada em 5 de outubro de 1988: acompanhada de disposições anteriores. 2. ed. São Paulo: Ed. Oliveira Mendes, 1998.

BRASIL. Lei n. 9.394, de 20 de dezembro de 1996. Estabelece as diretrizes e bases da educação nacional. Diário Oficial da República Federativa do Brasil, Brasilia, DF, 23 dez. 1996.

CUNHA, L. A. Educação, Estado e democracia no Brasil. São Paulo: Cortez; Niterói: EdUFF; Brasilia, DF: FLACSO, 2001.

ESCOLA do Futuro deve atender 5 mil crianças. Primeira Página, São Carlos, p. A3, 23 de junho de 2002. 
FERREIRA JÚNIOR, A.; BITTAR, M. A ditadura militar e a proletarização dos professores. Educação \&t Sociedade, v. 27, n. 97, p. 1159-1179, set./dez., 2006.

FREITAS, H. C. L. Certificação docente e formação do educador: regulação e desprofissionalização. Educação \&t Sociedade, Campinas, v. 24, n. 85, p.10951124, dez. 2003.

Formação de professores no Brasil: 10 anos de embate entre projetos de formação. Educação \&t Sociedade, Campinas, v.23, n. 80, p. 136-167, 2002.

FRIEDMAN, M. Capitalismo e liberdade. 2. ed. Tradução: Luciana Carli. São Paulo: Abril Cultural, 1984.

INEP. Censo escolar. Brasilia, DF, 2007. Disponivel em: <http://www.inep.gov.br/ basica/censo>. Acesso em: 26 jul. 2007.

. Mapa do analfabetismo no Brasil. Brasília, DF, 2003. Disponivel em: <http://www.inep.gov.br/estatisticas/analfabetismo>. Acesso em: 2 out. 2008.

MAURíCIO, L. V. Escritos, representações e pressupostos da escola pública de horário integral. Em Aberto, Brasilia, DF, v. 22, n. 80, p. 15-31, abr. 2009.

NEWTON anuncia mais 800 vagas em creches. Primeira Página, São Carlos, p. A3, fev. 2002.

NOGUEIRA, M. A. Um Estado para a sociedade civil: temas éticos e políticos da gestão democrática. São Paulo: Cortez, 2004.

PALHARES, M. S.; MARINS, S. C. (Org.). Escola inclusiva. São Carlos: EdUFSCar, 2002.

PARO, V. H. Eleição de diretores: a escola pública experimenta a democracia. 2. ed. São Paulo: Xamã, 2003.

PARTIDO DOS TRABALHADORES. Diretório Municipal de São Carlos. Programa de educação e cultura para o município de São Carlos (gestão 2001-2004). São Carlos, 2001. Mimeografado.

PEREIRA, L. C. B. Gestão do setor público: estratégia e estrutura para um novo Estado. In: PEREIRA, L. C. B.; SPINK, P. K. (Org.). Reforma do Estado e administração pública gerencial. Tradução: Carolina Andrade. Rio de Janeiro: Ed. FGV, 1998. 
PINTO, J. M. R. Remuneração adequada do professor: desafio à educação brasileira. Revista Retratos da Escola, Brasília, DF, v. 3, n. 4, p. 51-67, jan./jun. 2009.

PREFEITURA entrega 117 computadores a Emebs. Primeira Página, São Carlos, p. A4, 14 mar. 2002.

PREFEITURA faz eleição para cargo de diretor. Primeira Página, São Carlos, p. A3, 5 jan. 2001.

SÃO CARLOS (SP). Câmara Municipal. Ata da Sessão Ordinária, de 4 de dezembro de 2001. São Carlos, 2001a.

Câmara Municipal. Ata da Sessão Ordinária, de 5 de março de 2002. São Carlos, 2002a.

. Decreto $n^{\circ} 11$, de 5 de fevereiro de 2003. Institui o Conselho de Escola na rede municipal de educação de São Carlos e dá outras providências. Diário Oficial da Prefeitura de São Carlos, São Carlos, 2003a.

. Prefeitura Municipal. Lei $n^{\circ}$ 12.917, de 6 de dezembro de 2001. Autoriza o Poder Executivo a celebrar convênio com creches filantrópicas do Município de São Carlos. Diário Oficial da Prefeitura de São Carlos, São Carlos, 2001b.

. Lei $n^{\circ} 12.968$, de 26 de março de 2002. Institui o programa denominado "Movimento de Alfabetização de Jovens e Adultos de São Carlos" e dá outras providências. Diário Oficial da Prefeitura de São Carlos, São Carlos, 2002b.

. Lei $n^{\circ} 13.175$, de 26 de junho de 2003. Autoriza o Poder Executivo a celebrar convênio de cooperação técnica com instituições de ensino, públicas ou privadas, para formação em nível superior dos professores e pajens municipais. Diário Oficial da Prefeitura de São Carlos, São Carlos, $2003 \mathrm{~b}$.

. Lei $n^{\circ} 13.339$, de 2 de junho de 2004. Autoriza o Poder Executivo a firmar convênio com Universidades, Centros Universitários e Instituições de Ensino Superior. Diário Oficial da Prefeitura de São Carlos, São Carlos, 2004a.

. Lei $n^{\circ} 13.486$, de 16 de dezembro de 2004. Dispõe sobre a organização administrativa da prefeitura municipal de São Carlos e da outras providencias. Diário Oficial da Prefeitura de São Carlos, São Carlos, $2004 b$. 
SÃO CARLOS (SP). Prefeitura Municipal. A participação que dá certo: São Carlos-SP (Gestão 2001-2004). São Carlos: Suprema Gráfica e Ed., 2004c.

Prefeitura Municipal. Secretaria Municipal de Educação e Cultura. Edital para eleição de diretores de creches, de 3 de janeiro de 2001. São Carlos, 2001c.

Prefeitura Municipal. Secretaria Municipal de Educação e Cultura.

Portaria 003/01, de 8 de março de 2001. Institui critérios sobre as inscrições para eleição para o processo de composição das listas tríplices para a eleição de Diretor (a) de Escola Municipal de Educação Infantil e Escola Municipal de Educação Básica e dá outras providências. Diário Oficial da Prefeitura de São Carlos, São Paulo, (SP). São Carlos, 2001d.

SÃo Carlos fica em $377^{\circ}$ em escolaridade. Primeira Página, São Carlos, p. B1, 12 mar. 2009.

SÃO PAULO (Estado). Fundação Sistema Estadual de Análise de Dados. Anuário Estatístico do Estado de São Paulo. São Paulo, 2003. Disponivel em: <http:// www.seade.gov.br>. Acesso: 22 set. 2008.

SAVIANI, D. Formação de professores: aspectos históricos e teóricos do problema no contexto brasileiro. Revista Brasileira de Educação, Rio de Janeiro, v. 14, n. 40, p. 143-155, jan./abr., 2009.

SAVIANI, D. 0 Plano de Desenvolvimento da Educação: análise do projeto do MEC. Educação \&t Sociedade, Campinas, v. 28, n. 100 (Especial), p. 1231-1255, out. 2007.

SILVA, A. P. R. A política educacional do primeiro governo petista de São Carlos (2001-2004). 2009. 152 f. Dissertação (Mestrado em Educação) - Centro de Educação e Ciências Humanas, Universidade Federal de São Carlos, São Carlos, 2009.

SOUZA, D. S. B. Eleição de diretores escolares no município de São Carlos: propostas e polêmicas. 2005. 140 f. Dissertação (Mestrado em Educação) Centro de Educação e Ciências Humanas, Universidade Federal de São Carlos, São Carlos, 2006.

Recebido em: 22/02/2010

Aceito para publicação em: 04/05/2010 